\title{
Shaping space in practical therapy
}

\section{Piotr Gleń}

p.glen@pollub.pl

Independent Architectural Design Studio, Faculty of Civil Engineering and Architecture, Lublin University of Technology

\begin{abstract}
The authors of this article present issues concerning not only disability but also rehabilitation, which allows the disabled to become more independent. The principal aim of this article is to discuss the problem of the handicapped who have to face the world that is still non-adapted to their needs in terms of architecture. Hence, this paper is focused particularly on the role of designers creating the space surrounding the disabled who strive for returning to normal active life.
\end{abstract}

Keywords: disability, rehabilitation, therapeutic rehabilitation, social and professional rehabilitation.

\section{Introduction}

The authors of this article emphasize the variety of rehabilitation processes and, simultaneously, related requirements concerning the space, colours, and functional layouts. It is also of utmost importance that rehabilitation buildings or areas always have to be provided with additional rooms, otherwise such premises could not function normally. This article also addresses serious problems encountered not only by architects but also users, e.g. members of staff, rehabilitated persons, and carers. By focusing on selected examples of different types of disability, the authors of this article demonstrate sample solutions which can improve and speed up the process of returning to living normal and active social life.

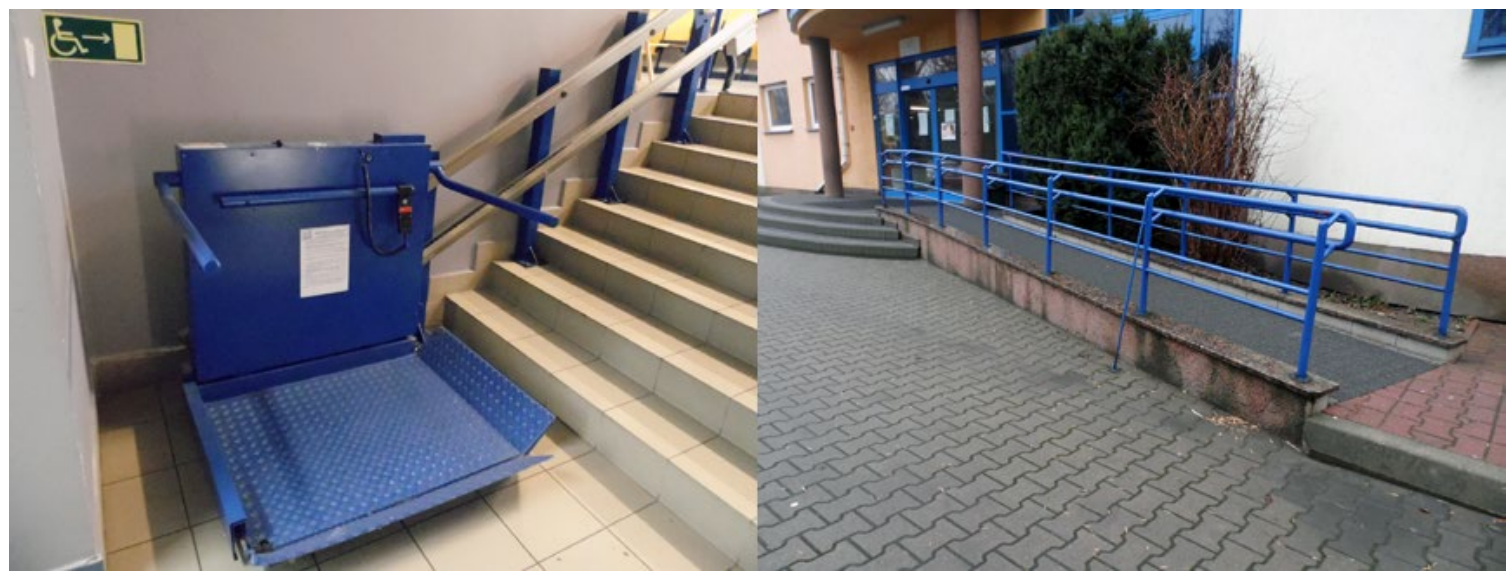

Fig. 1. A rake and a ramp for a disabled person. (photo: author)

The issue of designing objects with a function intended for people with reduced mobility is a challenge not only in terms of formal but also aesthetic. Nowadays, often there are different types of design solutions (Figure 1) in facilities for the needs of people with dysfunctions such as, for example, railyards or ramps. Requirements for buildings that serve rehabilitation purposes are determined not only by the Regulation of the Minister of Infrastructure regarding technical conditions that should be met by buildings and their location of 
April 12, 2002 (Journal of Laws No. 75, item 690) or the Construction Law but in the case of willingness to provide medical rehabilitation services financed from public funds through the Regulation No. 53/2010 / DSOZ of the President of the National Health Fund of September 2, 2010 on defining conditions for the conclusion and implementation of contracts in terms of medical rehabilitation. In addition to medical rehabilitation, aimed at helping a disabled person to achieve the greatest possible physical fitness, one should also look at centers specializing in social and professional rehabilitation, equally important in the event of a person's return to functioning in both the professional and private sphere. The authors of this article will introduce the meaning of the word «disabled person» to on this basis bring closer the existence of centers specializing in various types of rehabilitation. They will quote some of the requirements as well as, in order to prove that it is possible to meet the needs of both an investor and a user, present an example of a rehabilitation center that fulfills its function in terms of both formal and technical as well as aesthetic.

\section{The definition of disability}

The Act of 27 August 1997 on vocational and social rehabilitation and employment of disabled persons stipulates that it concerns «(...) persons whose physical, mental or mental condition permanently or periodically impedes, limits or prevents the performance of social roles, in particular the ability to perform professional work « [1]. Three degrees of disability were distinguished: «significant, moderate, light» [2]. In the same act, the definition of rehabilitation of disabled people was defined as «(...) a set of activities, in particular organizational, therapeutic, psychological, technical, training, educational and social, aimed at achieving, with the active participation of these people, the highest possible level of their functioning , quality of life and social integration" [3]. The participation in '(...) occupational therapy workshops, rehabilitation stays [and - author's note] physical exercise, psychoactive, recreational and sporting teams and other social activity teams according to the needs of disabled people" [4] was considered the basic forms of social rehabilitation. Published by the World Health Organization in 2001, the International Classification of Functioning, Disability and Health [5] states that «disability serves as a broad term encompassing all impairments in functioning, limiting participation and limiting participation» [6]. The above definitions indicate that disability does not refer only to limited mobility as it is usually perceived but includes various limitations of both physical and social functions.

\section{Requirements for facilities providing rehabilitation services}

Requirements and conditions for the provision of services in the field of medical rehabilitation (financed from public funds) are set out in Regulation No. 53/2010 / DSOZ of the President of the National Health Fund of September 2, 2010 on defining conditions for the conclusion and implementation of contracts in the field of rehabilitation, where it was determined that services in the field of medical rehabilitation can be "carried out in outpatient, home, daily and stationary settings» [7]. The said document (along with subsequent amendments) also defines the requirements (including personnel, premises or work time) for institutions providing the aforementioned services. Annex 3 to the said ordinance specifies the conditions for the provision of benefits in specific areas of contracted services. Requirements have been specified in relation to housing conditions, such as the need to place handrails and handles in sanitary facilities (Fig. 2.) for beneficiaries or the need to provide commuting and access to buildings adapted for people with reduced mobility. In the case of cardiac rehabilitation, attention was also paid to the need to place recreational rooms inside and outside the building [8]. These guidelines regarding the adaptation of the facility to the needs of users with reduced mobility are also included in the Regulation of the Minister of Infrastructure on technical conditions that should be met by buildings and their location of April 12, 2002 (Journal of Laws No. 75, item 690). An example may be a fragment regarding sanitary and hygienic rooms: «In the building, on floors accessible for the disabled, at least one of the generally accessible sanitary rooms should be adapted for these people by:

1. providing a maneuvering space of at least $1.5 \times 1.5 \mathrm{~m}$,

2. using doors without thresholds in these rooms and on the route, 
3. installing a suitably adapted, at least one toilet bowl and washbasin, as well as one shower if, due to the purpose, such devices are planned in the building,

4. installing brackets to enable the use of sanitary facilities. [9]"

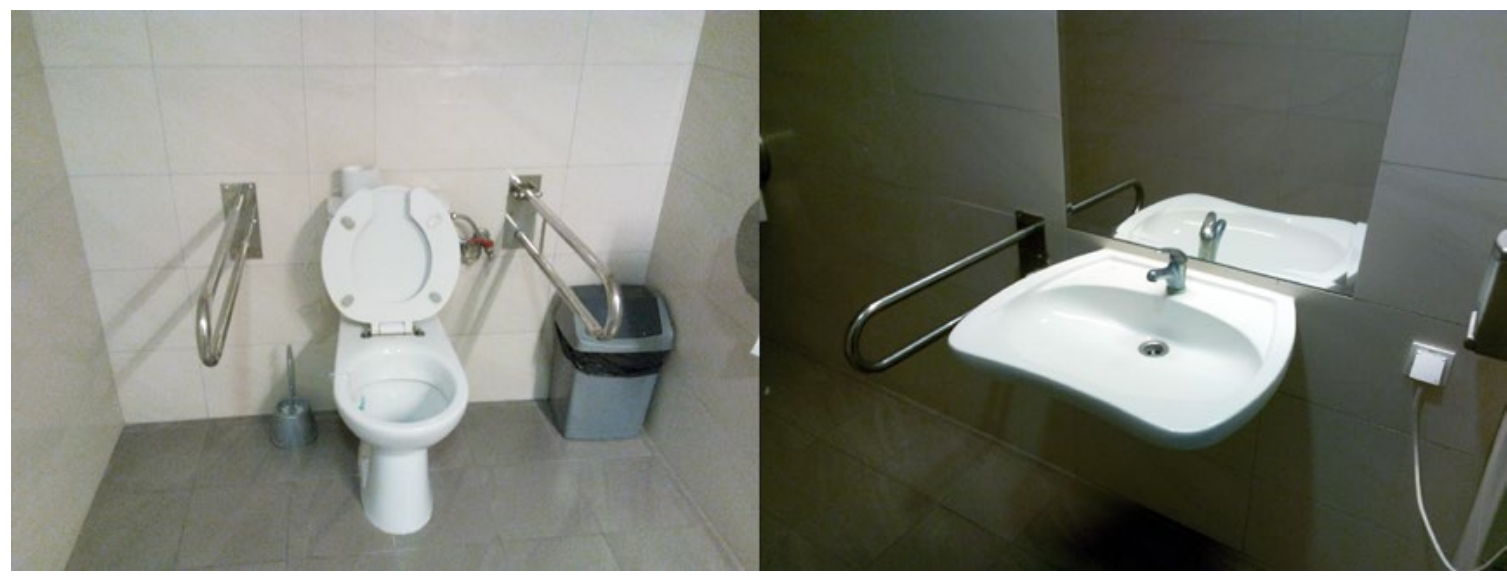

Fig. 2. Handrails in the toilet for a disabled person. (photo: author)

In addition to technical or legal requirements, the task of the architect is also to find solutions that can facilitate the disabled person's return to life outside the rehabilitation center. With regard to a user with reduced mobility, the availability of individual levels in a building or the adjustment of toilets plays an important role. However, there are also other groups such as blind people for whom the perception of space differs significantly from that of a healthy person. In the case of such limitations, it is necessary to create surfaces that are easy to remember, marked in a suitable way both by using various materials to help distinguish between individual spaces and described in a suitable way (examples may be descriptions in Braille). Deaf and deaf-mute people also have to face a number of difficulties, in these cases the color plays a particularly important role. An architect who develops centers addressed to a given group must demonstrate special empathy and understanding. Universal design should find a special place here, so that the proposed spaces at a later time do not have to be adapted to specific groups. A remarkable article referring to the functioning of disabled people is the one by Agnieszka Kłopotowska, where the author draws attention to the blind and the way in which the other senses are able to help in the reception of space [10]. There are a number of possibilities that can facilitate the specific return to life of these users and adaptation to a world adapted for healthy people.

\section{Occupational therapy centers as an element of rehabilitation}

In the article published in 2000, «Medical rehabilitation - its goals, assumptions and practical meaning» Irena Karwat and Andrzej Skwarcz described that «(...) it aims to achieve psychophysiological efficiency as quickly and efficiently as possible in the current situation of a sick person. Medical rehabilitation is closely connected on the one hand with methods of treatment, and on the other with social and psychological rehabilitation [11]". The need to return to relative, possible efficiency and gain social independence can be considered the primary, overarching goal of rehabilitation, but this does not mean that the less important aspect is the adaptation to life in society or the acquisition of skills enabling the performance of specific functions, including in the professional sphere. In connection with the above, the presence of centers specializing in occupational therapy should be emphasized; their advantages were noted by Anna Celińska-Pietrzak describing that «it can simultaneously operate on three different levels - physical, consisting mainly of rehabilitation, psychological, because the appropriate adjustment of exercise enables a disabled person to accept their disability and social one because they learn to live in a way that their health allows. [12]" In the Act on Vocational and Social Rehabilitation and Employment of People with Disabilities along with rehabilitation stays, these occupational therapy workshops have been included in the basic forms of activity supporting the process of vocational and social rehabilitation. 
[13] These centers are characterized by a wide spectrum of activities carried out in them not only in the field of medical rehabilitation with the use of rehabilitation equipment but also in the non-medical field such as artistic, tailor, ceramic or other activities aimed at achieving practical skills by those in its care. The fact of compiling a large number of the building's purposes as well as the need to fully adapt them so that they serve people with limited mobility or vision makes them a particularly difficult subject in terms of design.

\section{A positive example of a building intended for rehabilitation purposes}

Despite the difficulties and limitations faced by the designer deciding to develop a building with these goals, it is possible to achieve a satisfactory result for both the users and the investor as well as the architect himself. As an example of positive solutions, the authors of this article would like to present a center for social and professional rehabilitation of the Foundation «Family Home Rehabilitation of Children with Cerebral Palsy» in Opole. A project prepared by M. and A. Domicz Pracownia Architektury, which in 2014 won the Honorary SARP Award for design activity, which is carried out mainly in Opole [14].

The center, thanks to the aesthetics of the authors and their awareness of the problems faced by people requiring rehabilitation, is not only a distinctive building in terms of style but, more importantly, functional. It should be noted that the Foundation received the object as requiring immediate renovation. A former kindergarten, with a one-story block located in the industrial and warehouse district of the city, underwent a kind of metamorphosis. Reconstruction included adding a story in a building fragment to create a form of two interpenetrating solids. From the original assumption, only fragmentary elements of walls and ceilings have been preserved.

In the case of adjusting the facility for the needs of people with disabilities, the interior layout and their above-mentioned functionality are of particular importance. The authors of the described project managed to obtain this effect by separating the function. The ground floor, which largely houses classrooms, training rooms and a large multi-purpose hall, has been designed to suit the needs of users with limited mobility. On the first floor there are administrative rooms, which do not have to be available for those in the care of the center. Through this solution, the authors of the project could afford to narrow the corridor and the location of footbridges leading to individual rooms. This creative idea allowed to include more light in the corridor on the ground floor as well as made the space visually larger. The aesthetics of the building is simple, almost ascetic based on natural façade materials interwoven with glass panes [15].

Currently, the Vocational Activation Center runs a number of workshops in which disabled people can acquire professional skills, including printing, sewing, artistic, ceramic and others. They employ people with disabilities to a varying degree, including a significant degree. Qualifications that the employees of the center achieve allow them to find jobs in the current job market [16].

The above-mentioned example proves not only that with a highly developed sense of aesthetics and empathy, while maintaining the existing standards and regulations in Polish conditions, it is possible to complete a facility specializing in both professional and social as well as medical rehabilitation. The fact that people with disabilities are permanently employed in the above-mentioned center proves the need to locate similar places on the map of the country.

\section{Conclusions}

The problem of disability, although sometimes limited only to people with reduced mobility, refers to a wide range of both physical and mental limitations. Depending on the type of problem faced by a person affected by disability, there are a number of different forms of rehabilitation aimed at helping the patient return to independent functioning both in the field of healing rehabilitation as well as social or professional. All of these spheres have an impact on the subsequent functioning of this person in society. And it is there that the purpose of the existence of rehabilitation centers appears. In her article, Agnieszka Kłopotowska appreciates their existence because, as she points out (in relation to the visually impaired): «staying in a rehabilitation center is an extremely important stage, preceding the independence of the blind in everyday reality. The experiences 
gathered in this space teach openness, the ability to overcome further barriers, and overcome difficulties [17]." A similar statement can be applied to all places specializing in restoring the fitness of the blind and visually impaired as well as the deaf, and those with limited mobility or with all kinds of psychological problems. The space in which these people will come back to relative health is of great importance, as regards accessibility, clean functional layout or materials used, and additional amenities. With all the requirements an architect can not forget about aesthetics and costs, which in the case of modern solutions directed to particular disability groups can significantly increase the project costs. The projects carried out so far prove, however, that a compromise is possible in this matter.

\section{Literature}

[1] The Act of 27 August 1997 on vocational and social rehabilitation and employment of disabled persons, Journal of Laws No 123, pos. 776, Chapter 1 General Provisions, Art. 1

[2] Ibid., Chapter 2 Disability Evaluation, Art. 3;

[3] Ibid., Chapter 3 Rehabilitation of Disabled Persons, Art. 7;

[4] Ibid., Chapter 3 Rehabilitation of Disabled Persons, Art. 10;

[5] ICF International classification of functioning, disability and health, World Health Organization, 2011, http://www.csioz. gov.pl/src/files/klasyfikacje/ICF_Polish_version.pdf (accessed: 10.12.2014);

[6] Ibid., s. 3;

[7] Regulation No. 53/2010 / DSOZ of the President of the National Health Fund of September 2, 2010 on defining conditions for the conclusion and implementation of contracts in the field of rehabilitation, http://www.nfz.gov.pl/new/ index.php?katnr=3\&dzialnr=12\&artnr=4202 (accessed: 10.12 .2014 );

[8] Ibid.

[9] Regulation of the Minister of Infrastructure on technical conditions that should be met by buildings and their location of April 12, 2002 (Journal of Laws No. 75, item 690)

[10] A. Kłopotowska, Invisible architecture - the status of beauty beyond the visual perception of architectural space (in:) Czasopismo Techniczne. Architektura, edition. 6-A/2007, Kraków 2007, p. 269-274;

[11] Progress in Medical Sciences 3/2000, Borgis publishing house, available at: czytelniamedyczna.pl http://www.czytelniamedyczna.pl/2842,rehabilitacja-medyczna-jej-cele-zalozenia-i-znaczenie-praktyczne.html\# (accessed: 10.12.2014);

[12] Celińska-Pietrzak A., Occupational therapy as an integral part of the education of disabled people (in :) C. Kosakowski, ks. C. Rogowski (edit.), Multidimensionality of education of people with disabilities, published by. University of Warmia and Mazury in Olsztyn, Olsztyn 2005, p.163.

[13] The Act of 27 August 1997 on vocational and social rehabilitation op. cit., Chapter 3, Rehabilitation of Disabled Persons, Art. 10;

[14] Honorary SARP Award (in:) „ARCH. Magazyn Architektoniczny SARP”, 2014, no. 6(26), p. 14-26;

[15] Domicz A., Copyright assumptions of "M. i A. Domicz - pracownia architektury”, a text prepared for the purpose of building publication in no 7/2004 of ARCHITEKTURA - Murator monthly;

[16] Website of the Center for Social and Professional Rehabilitation of the Foundation «Family Home Rehabilitation of Children with Cerebral Palsy» in Opole http://zaz.opole.pl/index.php? $n=$ Pracownie (access: 10.12.2014);

[17] Kłopotowska A., A space for learning space. The art of visually impaired and blind-friendly design (in:) Czasopismo Techniczne. Architektura, edition. 7-A2, Kraków 2010, p. 168. 